\title{
DENSITOMETRY IN EVALUATION OF HERPETIC KERATITIS CORNEA CHANGES
}

Sakovich V. N., Nikitchina T. S., Sherbakov B. D.

Dnepropetrovsk, Ukraine

Cornea densitometry data of patients with herpetic keratitis and healthy corneas are given. By applying the anterior segment analyzer Pentacam HR (OCULUS) noncontact and quick corneal optic density imagination is possible. In cases of superficial herpetic keratitis the mean densitometry index is equal to $46.2 \pm 4.2 \mathrm{~d}$.un., in cases of deep forms $-50.8 \pm 10.2$ d.un. Mean densitometry index of healthy corneas is equal to $17.8 \pm 2.4$ d.un. The anterior segment analyzer allows to evaluate pathologic changes of the cornea and to control the effectiveness of treatment in dynamics.

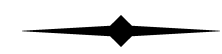

УДК 617.753.3:617.741-004.1-053.9-085.837.3

\section{ЗНАЧЕНИЯ ПОКАЗАТЕЛЯ ХИРУРГИЧЕСКИ ИНДУЦИРОВАННОГО АСТИГМАТИЗМА ПОСЛЕ ФАКОЭМУЛЬСИФИКАЦИИ В ЗАВИСИМОСТИ ОТ ВНУТРИГЛАЗНОГО ДАВЛЕНИЯ и Ригидности Роговицы}

\author{
В. А. Коломиец, д-р мед. наук, С. К. Дмитриев, д-р мед. наук, \\ ю. М. Лазарь, врач
}

гУ «Институт глазных болезней и тканевой терапии им. В. П. Филатова НАМН Украины»

\begin{abstract}
Вивчено показники хірургічно індукованого астигматизму через 1-3 місяці після проведення операції факоемульсифікації з імплантацією ІОЛ у хворих катарактою. Встановлено, що після факоемульсифікації з імплантацією ІОЛ значення хірургічно індукованого астигматизму знаходяться в діапазоні від 0,04 до 3,76 дптр. Виникнення хірургічно індукованого астигматизму після факоемульсифікації з імплантацією ІОЛ залежить не тільки від розміру розтину та його розташування, але і від величини передопераційного астигматизму рогівки, ригідності рогівки, величини внутріочного тиску, а також віку хворого.
\end{abstract}

Ключевые слова: хирургически индуцированный астигматизм, катаракта, факоэмульсификация, интраокулярная линза, астигматизм роговицы, внутриглазное давление, ригидность роговицы.

Ключові слова: хірургічно індукований астигматизм, катаракта, факоемульсифікація, інтраокулярна лінза, астигматизм рогівки, внутріочний тиск, ригідність рогівки.

Введение. В современной офтальмологии большое значение придают хирургическим приемам, направленным на коррекцию астигматизма с целью получения высококачественного зрения без дополнительной коррекции [12]. При операции факоэмульсификации (ФЭ) применяют ряд основных методик, предусматривающих коррекцию астигматизма: выбор локализации и ширины туннельного самоадаптирующегося разреза роговицы с учетом ее сильного меридиана, роговичные или лимбальные релаксирующие разрезы, «оппозитные» («противоразрезы») туннельные самоадаптирующиеся роговичные разрезы («Opposite Clear Corneal Incisions»), торические интраокулярные линзы (ИОЛ) [2]. Но даже технически идеально выполненная ФЭ с имплантацией искусственного торического хрусталика может не во всех случаях приводить к полной коррекции астигматизма и, соответственно, к высоким зрительным функциям.
Неполная послеоперационная коррекция астигматизма возможна при неточном прогнозе хирургически индуцированного астигматизма (ХИА). На величину ХИА одновременно может влиять большое количество факторов (возраст больного, локализация и ширина разреза, длина глазного яблока, уровень внутриглазного давления и прочие факторы). Вопрос о точности расчета ХИА после ФЭ остается дискуссионным. Исследователи отмечают широкий разброс данных, который может приводить к ошибке при планировании клинической рефракции глаза $[4,9]$.

Так, по данным Alio J., Pinero D. (2011), величина ХИА может составлять от 0,56 до 4,12 дптр при величине туннельного разреза роговицы 2,7 мм [11]. По данным Masket S. (2009 г.), значение ХИА при разрезе величиной 2,2 мм, выполненном в темпоральном квадранте роговицы, составило

() В. А. Коломиец, С. К. Дмитриев, Ю. М. Лазарь, 2012 
$(0,32 \pm 0,2)$ дптр [8]. В то же время, по данным клинического исследования Ernest P., Hill W. и Potvin R. (2011 г.), значение ХИА при разрезе величиной 2,2 мм, выполненном в темпоральном квадранте роговицы разными хирургами, составило от $(0,38 \pm 0,23)$ до $(0,88 \pm 0,6)$ дптр [3]. Jacob А. Т. (2012 г.) показал, что при использовании разреза 2,2 мм ХИА превышает 0,5 дптр в 24,0\% случаев [7].

Таким образом, указанный выше большой разброс данных ХИА может влиять как на ошибку в расчете конечной клинической рефракции после ФЭ, так и на выбор оптимальной модели торической интраокулярной линзы, в формуле расчета которой используется величина планируемого ХИА. Прогноз ХИА также чрезвычайно важен при имплантации «премиум» ИОЛ - мультифокальных и аккомодирующих - для которых низкие показатели остаточного астигматизма являются обязательным условием успешного проведения операции.

Цель настоящего исследования - изучить показатели хирургически индуцированного астигматизма после выполнения операции факоэмульсификации катаракты с имплантацией интраокулярной линзы в зависимости от возраста больного, локализации и размера туннельного разреза роговицы при факоэмульсификации, данных предоперационного астигматизма роговицы, длины переднезадней оси (ПЗО) глаза, толщины и ригидности роговицы, внутриглазного давления (ВГД).

МАТЕРИАЛ И МЕТОДЫ. Представлены результаты обследования, хирургического лечения и послеоперационного наблюдения за 76 больными, которым было произведено оперативное вмешательство - ФЭ катаракты с имплантацией ИОЛ (111 глаз) в возрасте от 17 до 83 лет, в среднем - 56,7 лет. При этом в возрасте до 40 лет было 13 человек $(17,1 \%)$, от 40 до 69 лет - 38 (50,0\%), от 70 и более лет - 25 человек $(32,9 \%)$. Из общего числа больных мужчин было 34 (44,7 \%), женщин 42 (55,3 \%). В исследование не включались больные катарактой, осложненной сопутствующей глазной патологией, а также с интраоперационными осложнениями. Оперативное вмешательство проводилось на правом глазу в $56(50,5 \%)$ случаях, на левом глазу - в 55 (49,5\%).

Визометрия до операции показала, что среди 111 обследованных глаз на $34(30,6 \%)$ острота зрения была 0,3 и выше, на 70 (63,1 \%) глазах - от 0,01 до 0,2, в 7 случаях (6,3\%) определялось светоощущение с правильной светопроекцией.

Средняя острота зрения у 104 больных с определяемым зрением составила $0,19 \pm 0,2$. Основная группа $(91,0 \%)$ прооперированных больных (111 человек) была со зрением от правильного светоощущения до 0,4, и 10 больных $(9,0$ \%) имели высокое зрение - от 0,5 до 1,0.

Кератометрические данные обследованных больных были получены с использованием кератотопографа «TMS4» («TOMEY»).

Преломляющая сила роговицы до операции у обследованных больных составила от 40,37 до 48,99 дптр со средним значением - $(43,8(1,5))$ дптр. Из них более чем в по- ловине случаев $(51,4 \%)$ рефракция роговицы находилась в пределах от 42,0 до 44,0 дптр, что характерно для глаз без аномалий рефракции. У $40,5 \%$ больных рефракция роговицы составляла от 44,0 до 49,0 дптр, что свойственно для глаз с гиперметропией и длиной передне-задней оси (ПЗО) менее 22,5 дптр. У остальных 8,1\% больных рефракция роговицы колебалась в пределах 40,0-42,0 дптр, что чаще всего встречается на глазах с длиной ПЗО более 24,0 мм, но с эмметропической рефракцией.

Величина астигматизма роговицы у обследованных больных до операции была от 0,08 до 4,8 дптр со средним значением - $(1,47(1,1))$ дाтр.

Минимальный астигматизм роговицы до 0,5 дптр, который не требует специальных хирургических мероприятий во время ФЭ с микроразрезами для профилактики возникновения ХИА, наблюдался только у 20,7 \% обследованных больных. В то же время у 18,9\% больных астигматизм роговицы составлял от 0,51 до 1,0 дптр, что требует специальных хирургических мероприятий во время ФЭ для профилактики ХИА или его интраокулярной коррекции, даже несмотря на то, что некоторыми авторами он считается физиологическим. Это особенно важно при использовании интраокулярных линз, способных обеспечивать ближнее зрение без дополнительной очковой коррекции. У 60,4\% больных диагностирован астигматизм роговицы более 1,0 дптр, который мог привести к существенному снижению остроты зрения после операции и требовал дополнительных хирургических приемов для его коррекции.

Длина передне-задней оси глаза до операции у обследованных больных была от 21,0 до 29,4 мм со средним значением - $(24,0(1,8))$ мм.

Для дальнейшего анализа результатов по длине ПЗО глаза прооперированные больные были разделены на три подгруппы. Количество гиперметропических глаз с длиной ПЗО до 22,5 мм составило 20 (18,0\%), миопических глаз длиной более 25,0 мм $-24(21,6 \%)$ и эмметропических длиной 22,6-24,9 мм - $67(60,4 \%)$.

Толщина роговой оболочки глаза до операции у обследованных больных колебалась в пределах от 482,0 до 611,0 мкм со средним значением - $(546,0(31,8))$ мкм. Эти показатели соответствуют нормальной толщине роговой оболочки глаза.

У больных возрастной катарактой перед проведением операции ФЭ с имплантацией ИОЛ показатель внутриглазного давления, измеренного по методу Маклакова, варьировал от 15,0 до 25,0 мм рт. ст. со средним значением - (19,1 $(2,3))$ мм рт. ст.. Внутриглазное давление, измеренное по методу Паскаля, составляло $14,3-24,0$ мм рт. ст. со средним значением - $(18,6(2,7))$ мм рт. ст.. Ригидность роговицы была от $(-4,2)$ до 3,9 мм рт. ст. со средним значением - $(0,4$ $(1,6))$ мм рт. ст. (табл. 1).

В исследуемой группе больных были имплантированы следующие модели ИОЛ Alcon AcrySof: SA60AT - 9 глаз, SN60WF - 20 глаз, SN6AD1-21 глаз, SN6AD3-4 глаза, SN60T3-14 глаз, SN60T4-18 глаз, SN60T5-22 глаза, SND1T4-1 глаз, SN6AT9-1 глаз, SND1T5-1 глаз.

Для проведения основного туннельного разреза использовались ножи-кератомы с величиной разреза 2,2 мм в $83(74,8 \%)$ случаях, величиной 2,75 мм - в $28(25,2 \%)$ случаях.

Поквадрантная локализация основного туннельного разреза роговицы была следующей: верхний квадрант -51 $(45,9 \%)$ глаз, верхне-темпоральный квадрант - 29 (26,1 \%) 
глаз, темпоральный квадрант $-2(1,8 \%)$ глаза и назальный квадрант -28 (25,2 \%) глаз.

Таблица 1

Внутриглазное давление (мм рт. ст.) и ригидность роговицы (мм рт. ст.) у больных до операции

\begin{tabular}{|c|c|c|c|c|c|c|}
\hline $\begin{array}{c}\text { Иссле- } \\
\text { дуемый } \\
\text { показа- } \\
\text { тель }\end{array}$ & $\begin{array}{c}\text { Сред- } \\
\text { нее }\end{array}$ & $\begin{array}{c}\text { Ме- } \\
\text { диана }\end{array}$ & $\begin{array}{c}\text { Мини- } \\
\text { мальное } \\
\text { значение }\end{array}$ & $\begin{array}{c}\text { Макси- } \\
\text { мальное } \\
\text { значение }\end{array}$ & SD & $\begin{array}{c}\text { Коли- } \\
\text { чество } \\
\text { наблю- } \\
\text { дений }\end{array}$ \\
\hline $\begin{array}{c}\text { ВГД по } \\
\text { Макла- } \\
\text { кову }\end{array}$ & 19,1 & 19,0 & 15,0 & 25,0 & 2,3 & 66 \\
\hline $\begin{array}{c}\text { ВГД по } \\
\text { Паска- } \\
\text { лю }\end{array}$ & 18,6 & 17,9 & 14,3 & 24,0 & 2,7 & 59 \\
\hline $\begin{array}{c}\text { Ригид- } \\
\text { ность } \\
\text { рого- } \\
\text { вицы }\end{array}$ & 0,4 & 0,7 & $-4,2$ & 3,9 & 1,6 & 59 \\
\hline
\end{tabular}

Определение рефракции и топографии роговицы проводилось на кератотопографе «TMS-4» («Тотеу») до операции, при выписке и при повторных контрольных осмотрах.

Ультразвуковую биометрию и пахиметрию осуществляли на приборе «OcuScan RXP» («Alcon», CША), при этом определяли длину ПЗО глаза, глубину передней камеры, толщину естественного хрусталика и роговицы. Перечисленные параметры использовались для расчета оптической силы ИОЛ. Оптическая сила имплантируемых ИОЛ для заданной рефракции рассчитывалась по стандартным формулам геометрической оптики с учетом «анатомических» параметров глаз.

Расчет силы цилиндрического компонента торической ИОЛ с определением оси локализации - проводился в режиме «on-line» на интернет-ресурсе www.acrysoftoriccalculator. com.

Внутриглазное давление (ВГД) измеряли по методам Маклакова и Паскаля. Измерение ВГД по методу Маклакова выполнялось тонометром весом 10 г. Определение ВГД по методу Паскаля выполнялось на тонометре PASCAL («Ziemer», Швейцария). Данный прибор в настоящее время является наиболее точным при измерении истинного ВГД. Разница между уровнями ВГД, измеренными по Маклакову и Паскалю, позволяет определить ригидность роговицы [5].

Для определения величины ХИА использовалась компьютерная программа «The SIA Calculator Version 2.1», paботающая в MS Excel и предложенная авторами Sawhney S., Aggarwal A.. В основе работы калькулятора лежит векторный анализ кератометрических пред- и послеоперационных данных (величины и направленности сильного и слабого меридианов роговицы) $[6,10]$. сяца.

Сроки наблюдения после операции составили 1-3 ме-

РЕЗУЛЬТАТЫ И ИХ ОБСУЖДЕНИЕ. Острота зрения в первые 3 дня после операции у обследуемых больных составила $(0,92(0,03))$. В последующем отмечалось повышение О3 до $(1,01(0,03))-$ через 1-3 месяца после операции, до $(1,05(0,03))$ через 4-6 месяцев и в дальнейшем оставалась на таком же уровне (табл. 2).
Таблица 2

Динамика остроты зрения у больных возрастной катарактой после факоэмульсификации с имплантацией ИОЛ

\begin{tabular}{|l|c|}
\hline \multicolumn{1}{|c|}{ Срок наблюдения } & Острота зрения \\
\hline $1-3$ дня & $0,92(0,03)$ \\
\hline $1-3$ месяца & $1,01(0,03)$ \\
\hline 4-6 месяцев & $1,05(0,03)$ \\
\hline Более 6 месяцев & $1,06(0,03)$ \\
\hline
\end{tabular}

Как следует из представленных данных, основным периодом достоверного $(\mathrm{p}=0,00002)$ повышения зрительной функции являются первые три месяца после операции ФЭ с имплантацией ИОЛ у больных возрастной катарактой. В более поздние сроки наблюдается незначительная тенденция $(p=0,05)$ к повышению остроты зрения. Поэтому можно считать правомерным проведение анализа полученных результатов именно в первые три месяца после операции, что соответствует и данным литературы о том, что время стабилизации роговичных разрезов составляет от 1 до 3 месяцев после операции [3].

Из 97 больных, обследованных через 1-3 месяца после операции, максимальную остроту зрения без дополнительной очковой коррекции показали 66 (68,0 \%) больных. Максимальная острота зрения с дополнительной очковой коррекцией - в $31(32,0$ \%) случае. Для получения максимальной остроты зрения сферическая коррекция была необходима в $8(8,2 \%)$ случаях, сфероцилиндрическая - в $8(8,2 \%)$ и цилиндрическая - в $15(15,6 \%)$ случаях.

Имплантация торической ИОЛ с целью коррекции исходного астигматизма роговицы была выполнена в 50 (51,5 \%) случаях. Необходимость дополнительной очковой коррекции с цилиндрическим компонентом наблюдалась в 13 случаях, т.е. в $13,4 \%$ от общего количества обследованных больных и в 26,0 \% у больных с имплантированными торическими ИОЛ через $1-3$ месяца после операции. До операции у 4 (8,0 \%) больных с торическими ИОЛ планировалось получение остаточного астигматизма из-за высоких величин предоперационного астигматизма от 3,7 до 4,3 дптр, который невозможно было полностью откорректировать имплантацией существующих в то время торических ИОЛ.

Таким образом, полученные данные послеоперационной остроты зрения свидетельствуют о высокой эффективности интраокулярной коррекции астигматизма. Однако 16,0 \% больных с имплантированными торическими ИОЛ, у которых планировалось получить максимальную О3, нуждались в дополнительной очковой цилиндрической коррекции.

Показатели ХИА в исследуемой группе больных в сроки 1-3 месяца после операции представлены на рисунке 1 . 


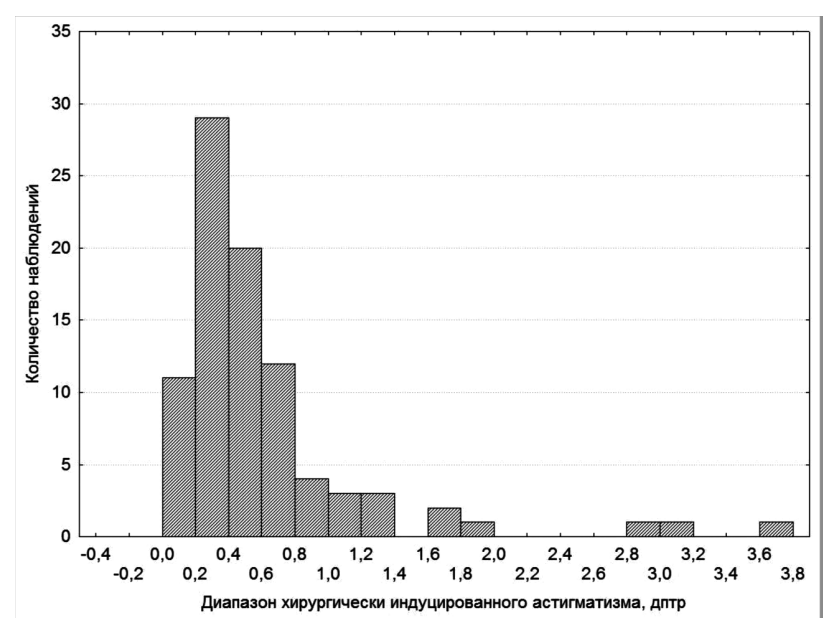

Рис. 1. Распределение показателей хирургически индуцированного астигматизма в исследуемой группе больных в сроки 1-3 месяца после операции

Диапазон значений ХИА, полученных через 1-3 месяца после операции, составил от 0,04 до 3,76 дптр (рис. 1.). У 86,4\% пациентов значения ХИА не превышали 1,0 дптр, в то же время у 13,6 \% больных значение ХИА находится в диапазоне от 1,06 до 3,76 дптр.

Для определения факторов, влияющих на значения ХИА, нами была проанализирована связь ХИА с возрастом больных, предоперационным астигматизмом роговицы, длиной ПЗО глаза, толщиной и ригидностью роговицы, уровнем ВГД, шириной и локализацией разреза при проведении ФЭ с имплантацией ИОЛ у больных возрастной катарактой.

В таблице 3 представлены значения ХИА через 1-3 месяца после операции в зависимости от возраста исследуемых больных.

Таблица 3

Значения хирургически индуцированного астигматизма через 1-3 месяца после операции в зависимости от возраста исследуемых больных

\begin{tabular}{|l|c|c|}
\hline Возраст, лет & $\begin{array}{c}\text { Количество } \\
\text { наблюдений } \\
(\mathbf{n = 8 8 )}\end{array}$ & $\begin{array}{c}\text { Хирургически } \\
\text { индуцированный астигматизм } \\
\text { (M (SD)), дптр }\end{array}$ \\
\hline До 40 & 12 & $1,12(1,15)$ \\
\hline $41-69$ & 48 & $0,52(0,39)$ \\
\hline 70 и более & 28 & $0,57(0,53)$ \\
\hline
\end{tabular}

Анализ зависимости ХИА от возраста больных показал, что у больных в возрасте до 40 лет значения ХИА статистически значимо выше, чем у больных в возрасте $41-69$ лет $(\mathrm{p}=0,003)$ и в возрасте 70 и более лет $(\mathrm{p}=0,003)$. Значения ХИА у пациентов в возрасте до 40 лет - $(1,12(1,15))$ дптр, от 41 до 69 лет $-(0,52(0,39))$ дптр и от 70 и более лет $-(0,57$ $(0,53))$ дптр (табл. 3). Учитывая полученные результаты, можно предположить, что больные молодого трудоспособного возраста составляют группу повышенного риска возникновения высокого ХИА более 1,0 дптр после проведения ФЭ с имплантацией
ИОЛ. Дальнейшее определение факторов, ведуших к возникновению высоких значений ХИА после операции, может привести к определению алгоритма ведения таких больных и проведения мероприятий по профилактике его развития.

В таблице 4 представлены значения ХИА через 1-3 месяца после операции на глазах с различной длиной ПЗО глаза.

Таблица 4

Значения хирургически индуцированного астигматизма через 1-3 месяца после операции в зависимости от длины переднезадней оси глаз у больных катарактой

\begin{tabular}{|l|c|c|}
\hline $\begin{array}{c}\text { Длина } \\
\text { переднезадней оси } \\
\text { глаза, мм }\end{array}$ & $\begin{array}{c}\text { Количество } \\
\text { глаз (n=88) }\end{array}$ & $\begin{array}{c}\text { Хирургически индуци- } \\
\text { рованный астигматизм } \\
\text { (M (SD)), дптр }\end{array}$ \\
\hline Менее 22,5 & 17 & $0,56(0,62)$ \\
\hline $22,5-25,0$ & 51 & $0,6(0,59)$ \\
\hline Более 25,0 & 20 & $0,69(0,69)$ \\
\hline
\end{tabular}

Анализ значений ХИА у больных с различной длиной ПЗО глаза не выявил статистически значимых различий $(\mathrm{p}>0,05)$ у больных трех различных групп. Значения ХИА в группе больных с длиной ПЗО глаза менее 22,5 мм составили $(0,56$ $(0,62))$ дптр, на глазах с длиной ПЗО от 22,5 до 25,0 мм - $(0,6(0,59))$, более 25,0 мм - $(0,69(0,69))$ дптр (табл. 4). Полученные показатели подтверждают данные, опубликованные ранее другими исследователями [1].

В таблице 5 представлены значения ХИА в зависимости от степени предоперационного астигматизма роговицы.

Таблица 5

Значения хирургически индуцированного астигматизма через 1-3 месяца после операции в зависимости от степени предоперационного астигматизма роговицы глаз у больных катарактой

\begin{tabular}{|l|c|c|}
\hline $\begin{array}{c}\text { Предоперационный } \\
\text { астигматизм } \\
\text { роговицы глаза, дптр }\end{array}$ & $\begin{array}{c}\text { Количество } \\
\text { глаз (n=88) }\end{array}$ & $\begin{array}{c}\text { Хирургически индуциро- } \\
\text { ванный астигматизм (M } \\
\text { (SD)), дптр }\end{array}$ \\
\hline До 1,0 & 36 & $0,41(0,22)$ \\
\hline От 1,0 до 2,0 & 34 & $0,7(0,57)$ \\
\hline Более 2,0 & 18 & $0,86(1,02)$ \\
\hline
\end{tabular}

Анализ значений ХИА в зависимости от исходного предоперационного астигматизма роговицы показал, что при предоперационном астигматизме роговицы до 1,0 дптр значение ХИА составляет $(0,41(0,22))$ дптр, при астигматизме от 1,0 до 2,0 дптр - $(0,7(0,57))$ дптр, при астигматизме более 2,0 дптр - $(0,86(1,02))$ дптр (табл. 5). В группе больных с высоким (более 2,0 дптр) исходным астигматизмом выявлено статистически значимое $(p=0,02)$ увеличение значений ХИА сравнительно с больными с низким астигматизмом - до 1,0 дптр. У больных с исходным астигматизмом установлена тенденция $(p=0,08)$ к повышенным значениям ХИА 
сравнительно с больными с низким астигматизмом до 1,0 дптр. Полученные данные показывают, что чем выше предоперационный астигматизм роговицы, тем выше значение ХИА. Это может быть связано с тем, что роговая оболочка глаза с исходной деформацией более подвержена послеоперационным изменениям ее формы, чем сферическая роговица.

В таблице 6 представлены значения ХИА через 1-3 месяца после операции у больных в зависимости от величины основного туннельного разреза роговицы.

Таблица 6

Значения хирургически индуцированного астигматизма через 1-3 месяца после операции в зависимости от величины основного туннельного разреза роговицы

\begin{tabular}{|c|c|c|}
\hline $\begin{array}{c}\text { Величина } \\
\text { разреза, мм }\end{array}$ & $\begin{array}{c}\text { Количество } \\
\text { наблюдений } \\
\text { (n=87) }\end{array}$ & $\begin{array}{c}\text { Хирургически } \\
\text { индуцированный астигматизм } \\
\text { (M (SD)), дптр }\end{array}$ \\
\hline 2,2 & 68 & $0,49(0,42)$ \\
\hline 2,75 & 19 & $1,05(0,95)$ \\
\hline
\end{tabular}

Изучение зависимости величины ХИА от величины основного туннельного разреза роговицы показало, что при разрезе величиной 2,2 мм значение ХИА составляет $(0,49(0,42))$ дптр, в то время как при разрезе величиной 2,75 мм значение ХИА статистически значимо $(\mathrm{p}=0,0004)$ выше и составляет $(1,05(0,95))$ дптр. Из приведенных данных следует, что использование разрезов роговицы величиной 2,2 мм во время проведения ФЭ способно уменьшить риск развития ХИА высокой степени. В то же время, применение разрезов роговицы величиной 2,75 мм с локализацией в сильном меридиане астигматизма способно существенно уменьшать исходный астигматизм роговицы и может быть использовано с целью лечения исходного астигматизма роговицы.

Следующим шагом было изучение зависимости величины ХИА от локализации разреза в сильном и слабом меридианах роговицы (табл. 7).

Таблица 7

Значения хирургически индуцированного астигматизма через 1-3 месяца после операции в зависимости от локализации разреза в различных по силе меридианах роговицы

\begin{tabular}{|l|c|c|}
\hline Меридиан роговицы & $\begin{array}{c}\text { Количество } \\
\text { наблюдений } \\
\text { (n=87) }\end{array}$ & $\begin{array}{c}\text { Хирургически индуциро- } \\
\text { ванный астигматизм (M } \\
\text { (SD)), дптр }\end{array}$ \\
\hline Сильный & 46 & $0,8(0,78)$ \\
\hline Промежуточный* & 28 & $0,45(0,25)$ \\
\hline Слабый & 13 & $0,3(0,16)$ \\
\hline
\end{tabular}

Примечание: *между сильным и слабым меридианом роговицы

В результате проведенного анализа показателей ХИА в зависимости от локализации основного туннельного разреза в различных по силе меридианах роговицы установлено, что значения ХИА при локализации разреза в сильном меридиане рого- вицы - $(0,8(0,78))$ дптр статистически значимо выше, чем при разрезе в слабом меридиане - $(0,3$ $(0,16))$ дптр $(p=0,015)$ и в промежуточном меридиане (между сильным и слабым меридианом) - $(0,45$ $(0,25))$ дптр $(\mathrm{p}=0,01)$. Значения ХИА при разрезе в слабом меридиане и при разрезе в промежуточном меридиане статически значимо не отличаются между собой $(\mathrm{p}=0,4)$.

В таблице 8 представлены значения ХИА при величине основного туннельного разреза 2,2 мм в зависимости от его локализации в различных по силе меридианах роговицы.

Таблица 8

Значения хирургически индуцированного астигматизма через 1-3 месяца после операции при величине основного тунельного разреза 2,2мм в зависимости от его локализации в различных по силе меридианах роговицы

\begin{tabular}{|l|c|c|}
\hline Меридиан роговицы & $\begin{array}{c}\text { Количество } \\
\text { наблюдений } \\
\text { (n=68) }\end{array}$ & $\begin{array}{c}\text { Хирургически индущиро- } \\
\text { ванный астигматизм (M } \\
\text { (SD)), дптр }\end{array}$ \\
\hline Сильный & 31 & $0,6(0,55)$ \\
\hline Промежуточный* & 26 & $0,45(0,25)$ \\
\hline Слабый & 11 & $0,29(0,17)$ \\
\hline
\end{tabular}

Примечание: *между сильным и слабым меридианом роговицы

Установлено, что при локализации разреза величиной 2,2 мм в сильном меридиане роговицы значение ХИА составило $(0,6(0,55))$ дптр, в промежуточном меридиане - $(0,45(0,25))$ дптр, в слабом меридиане роговицы - $(0,29(0,17))$ дптр (табл. 8.). Значение ХИА в сильном меридиане роговицы статистически значимо $(\mathrm{p}=0,06)$ выше, чем при разрезе в слабом меридиане роговицы. Полученные данные позволяют рекомендовать проведение ФЭ в сильном меридиане роговицы при потребности уменьшения исходного астигматизма роговицы. Но, в то же время, при имплантации торических ИОЛ, когда важен точный прогноз изменения кривизны роговицы после операции, предпочтительным является проведение ФЭ через разрез, расположенный в слабом меридиане роговицы.

Также исследовались значения ХИА после применения разреза величиной 2,2 мм в различных квадрантах роговицы (табл. 9.).

При локализации разреза величиной 2,2 мм в верхнем квадранте роговицы значение ХИА составило $(0,52(0,38))$ дптр, в верхне-темпоральном квадранте - $(0,58(0,59))$ дптр, в темпоральном $(0,41(0,0))$ дптр и в назальном - $(0,37(0,22))$ дптр (табл. 9.). Статистически значимых различий показателей ХИА при применении разреза величиной 2,2 мм в различных квадрантах роговицы не выявлено ( $>00,05)$. Таким образом, использование микроразрезов величиной 2,2 мм позволяет выполнять ФЭ с проведением разреза в любом удобном для хирурга квадранте роговицы без дополнительного риска развития высокого ХИА. 
Таблица 9

Значения хирургически индуцированного астигматизма через 1-3 месяца после операции при величине основного тунельного разреза 2,2 мм в зависимости от локализации в различных квадрантах роговицы

\begin{tabular}{|l|c|c|}
\hline \multicolumn{1}{|c|}{ Квадрант роговицы } & $\begin{array}{c}\text { Количество } \\
\text { глаз (n=68) }\end{array}$ & $\begin{array}{c}\text { Хирургически индуци- } \\
\text { рованный астигма- } \\
\text { тизм (М (SD)), дптр }\end{array}$ \\
\hline Верхний & 25 & $0,52(0,38)$ \\
\hline Верхне-темпоральный & 21 & $0,58(0,59)$ \\
\hline Темпоральный & 1 & $0,41(0,0)$ \\
\hline Назальный & 21 & $0,37(0,22)$ \\
\hline
\end{tabular}

\section{ЗАКЛЮЧЕНИЕ}

Таким образом, операция факоэмульсификации с имплантацией ИОЛ является высокоэффективным способом восстановления зрительных функций у больных возрастной катарактой уже в первые три месяца после операции. Однако, по нашим данным, 16,0 \% больных с имплантированными торическими ИОЛ, у которых планировалось получить максимальную О3, нуждались в дополнительной очковой коррекции с цилиндрическим компонентом. Для определения факторов, влияющих на восстановление зрения после операции, нами была изучена зависимость развития хирургически индуцированного астигматизма от возраста больных, величины предоперационного астигматизма роговицы, длины передне-задней оси глаза, толщины и ригидности роговицы, уровня ВГД, ширины и локализации разреза при проведении ФЭ с имплантацией ИОЛ у больных возрастной катарактой.

По нашим данным, риск развития высокого ХИА выше у молодых больных до 40 лет, у больных с высоким исходным предоперационным астигматизмом, высоким истинным ВГД и низкой ригидностью роговицы. Полученную зависимость можно объяснить тем, что глаза с изначально деформированной роговой оболочкой, высоким истинным ВГД и слабой сопротивляемостью факторам, ведущим к ее деформации, менее устойчивы к изменениям, связанным с интраоперационной травмой.

Основываясь на полученных результатах, для снижения риска развития высоких значений хирургически индуцированного астигматизма можно рекомендовать проведение ФЭ через разрез величиной 2,2 мм расположенный в слабом меридиане роговицы. При потребности уменьшения исходно- го астигматизма роговицы нужно рекомендовать проведение ФЭ через разрез величиной 2,75 мм, расположенный в сильном меридиане роговицы.

\section{ЛИТЕРАТУРА}

1. Новицький О. М. Клінічне дослідження можливості формування післяопераційного рогівкового астигматизму при екстракції катаракти через тунельні розрізи : автореф. дис. на здобуття наук. ступеня канд. мед. наук : спец. 14.01.18 / О. М. Новицький. - К., 2002. $-18 \mathrm{c}$.

2. Astigmatism management in cataract surgery with the AcrySof toric intraocular lens / N. Bauer, N. de Vries, C. Webers [et al.] // J. Cataract. Refract. Surg. - 2008. - Vol. 34, № 9. - P. 1483-1488.

3. Ernest P. Minimizing surgically induced astigmatism at the time of cataract surgery using a square posterior limbal incision // P. Ernest, W. Hill, R. Potvin // J. of Ophthalm. - 2011. - Vol. 2011 (2011). - Art.ID 243170-4 p.

4. Gills J. P. Combined toric intraocular lens implantation and relaxing incisions to reduce high preexisting astigmatism // J. P. Gills, M. Van der Karr, M. Cherchio // J. Cataract. Refract. Surg. - 2002. - Vol. 28, № 9. P. $1585-1588$.

5. Gontijo L. Corneal rigidity in numbers / http://escrs.conference2web.com/content/4496/ // 27 ${ }^{\text {th }}$ Congress of the ESCRS : - Barcelona, 2009.

6. Hill W. Expected effects of surgically induced astigmatism on AcrySof toric intraocular lens results / W. Hill // J. Cataract. Refract. Surg. - 2008. - Vol. 34, № 3 - P. 364-367.

7. Jacob A. Th. A study on the impact of $2,2 \mathrm{~mm}$ temporal clear corneal incision on astigmatism / http://www.mchophthal.com/pdf/Dr.Ashly \%20Thomas \%20Jacob.pdf

8. Masket S. Induced astigmatism with 2.2- and 3.0-mm coaxial phacoemulsification incisions // S. Masket, L. Wang, S. Belani // J. Refract. Surg. - 2009. - Vol. 25, № 1. P. 21-24.

9. Qammar A. Paired opposite clear corneal incisions to correct preexisting astigmatism in cataract patients / A. Qammar, P. Mullaney // J. Cataract. Refract. Surg. - 2005. Vol. 31, № 6. - P. 1167-1170.

10. Sawhney S. Theoretical validity of vector analysis for aggregate astigmatic data / S. Sawhney // J. Cataract. Refract. Surg. - 2002. - Vol. 28, № 3- P. 385-386.

11. Vector analysis of astigmatic changes after cataract surgery with toric intraocular lens implantation / J. Alio, D. Pinero, J. Tomas, A. Aleson // J. Cataract. Refract. Surg. 2011. - Vol. 37, № 6. - P. 1038-1049.

12. Werner L. New technology IOL optics / L. Werner, R. J. Olson // Ophthalmol. Clin. North Am. - 2006. Vol. 19, № 4. - P. 469-483.

Поступила 23.11.2012 Рецензент д. М. н. В. Я. Усов 


\title{
VALUES OF SURGICALLY INDUCED ASTIGMATISM AFTER PHACOEMULSIFICATION
}

DEPENDING ON THE IOP AND CORNEA RIGIDITY

\section{Kolomiets V. O., Dmytriiev S. K., Lazar Yu. M.}

Odessa, Ukraine

Values of surgically induced astigmatism after phacoemulsification with IOL implantation in patients with cataract were investigated.

It was established that after phacoemulsification with IOL implantation the value of surgically induced astigmatism was in the range from $0.04 \mathrm{D}$ to $3.76 \mathrm{D}$.

Surgically induced astigmatism after phacoemulsification with IOL implantation depends not only on the incision size and location. It also depends on anatomical-functional parameters of the eye among which it is possible to distinguish the degree of preoperative corneal astigmatism, corneal rigidity, IOP value as well as patient's age.

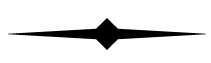

УДК 617.735-002+616.379-008.64]-036.65:617.741-004.1-089

\section{ДИНАМИКА ПРОГРЕССИРОВАНИЯ ДИАБЕТИЧЕСКОЙ РЕТИНОПАТИИ ПРИ САХАРНОМ ДИАБЕТЕ II ТИПА ПОСЛЕ УДАЛЕНИЯ КАТАРАКТЫ}

\author{
К. П. Павлюченко, д. М. Н., проф., Т. В. Олейник, д. М. Н., проф.,
}

\section{А. В. Коробова, асс.}

Донецкий национальный медицинский университет им. М. Горького

\begin{abstract}
Вивчено мохсливість профілактики виникнення діабетичної ретинопатії і уповільнення прогресування непроліферативної діабетичної ретинопатії у хворих з иукровим діабетом 2 типу після факоемульсифікації катаракти. Під наглядом протягом 3-х років перебували 82 хворих (91 очей) з иукровим діабетом 2 типу без діабетичної ретинопатії, з початковою та помірною непроліферативною діабетичною ретинопатією, які були прооперовані з приводу вікової катаракти. Встановлено, що застосування симвастатину дозволило уникнути прогресування діабетичної ретинопатії в 46,82\% випадків, в порівнянні з 27,27\% випадків у хворих, які отримували тільки стандартну терапію. При призначенні симвастатину частота розвитку важкої непролиферативної і проліферативної діабетичної ретинопатії в 2,9 разів менша.
\end{abstract}

Ключевые слова: диабетическая ретинопатия, катаракта, сахарный діабет II типа, симвастатин

Ключові слова: діабетична ретинопатія, катаракта, цукровий діабет II типу, симвастатин.

Введение. Диабетическое поражение сетчатки было и, к сожалению, остается лидирующей причиной слепоты среди лиц трудоспособного возраста в развитых странах $[1,13,17]$. Диабетическая ретинопатия (ДР) является одним из тяжелых проявлений сахарного диабета и приводит к снижению зрительных функций у 30-90 \% больных [7]. Особенно актуальной стала эта проблема для пациентов, страдающих сахарным диабетом II типа (СД II типа), число которых каждые 12-15 лет увеличивается в среднем вдвое, причем ДР развивается у 60-95\% этих больных [4, 6].

Наряду с диабетической ретинопатией, к снижению зрения у данной категории больных приводит и помутнение хрусталика, что существенно затрудняет диагностику, динамическое наблюдение, а также контроль эффективности лечения диабетических поражений сетчатки [21]. ДР при СД II типа сочетается с катарактой в 79,5 \% случаев [16]. Со- временные технические возможности микрохирургии катаракт, среди которых лидирующие позиции занимает факоэмульсификация, а также широкий выбор интраокулярных линз, позволяют эффективно оперировать катаракту у больных сахарным диабетом. Однако существует мнение о том, что даже идеально проведенная операция по удалению катаракты у пациентов с СД может спровоцировать возникновение и прогрессирование сосудистых осложнений на глазном дне [5, 23], что обусловлено патогенетическими особенностями СД и его осложнений, аутоиммунным характером заболевания, нарушением нейрогуморального и локального клеточного гомеостаза [12]. В связи с этим актуальным является поиск путей замедления прогрессирования ДР у пациентов после факоэмульсификации.

(c) К. П. Павлюченко, Т. В. Олейник, А. В. Коробова, 2012 